Supporting Information for

\title{
Design of $\mathrm{MoS}_{2} /$ Graphene van der Waals
}

\section{Heterostructure as Highly Efficient and Stable}

\section{Electrocatalyst for Hydrogen Evolution in Acidic}

\section{and Alkaline Media}

Xianbo Yu,,$^{\dagger}$ Guangyu Zhao, *, Shan Gong, ${ }^{\dagger}$ Chao Liu,,$^{\dagger}$ Canlong Wu,,$^{\dagger}$ Pengbo Lyu, *s Guillaume Maurin, ${ }^{\S}$ and Naiqing Zhang ${ }^{*, t}$

$\uparrow$ School of Chemistry and Chemical Engineering, Harbin Institute of Technology, Harbin, Heilongjiang, 150001, China

* Interdisciplinary Science Research Center, Harbin Institute of Technology, Harbin, Heilongjiang, 150001, China

§ ICGM, CNRS, ENSCM, Univ. Montpellier, Montpellier, 34095, France

*Corresponding Author

E-mail: Guangyu Zhang (zhaogy810525@gmail.com); Naiqing Zhang (znqmww@163.com); Pengbo Lyu (pengbo.lyu @umontpellier.fr) 


\section{Experimental Section}

\section{Chemicals}

The Graphene oxide (GO) was synthesized by Hummers' method and then allocated to a

$\mathrm{GO} /$ water homogeneous dispersion with the $\mathrm{GO}$ concentration of $1.0 \mathrm{mg} \mathrm{mL}^{-1}$. Moreover, all the relevant reagents in this work were purchase from Shanghai Aladdin biochemical technology co., LTD (China) without further treatment except potassium hydroxide aqueous electrolyte was purified.

\section{Preparation of $\mathrm{MoS}_{2} / \mathrm{G}$ HS}

The $\mathrm{MoS}_{2} / \mathrm{G}$ HS catalyst was synthesized as follows: First, $30 \mathrm{~mL}$ of negatively charged GO/water homogeneous was modified by the dispersed mixture solution, which was formed by $360 \mathrm{mg}$ of positively charged polyethyleneimine (PEI) and $20 \mathrm{~mL}$ distilled water. After stirred continuously for $24 \mathrm{~h}$, the products (PEI/GO) were centrifuged and washed several times by the distilled water. Second, the obtain PEI/GO dispersed in the $30 \mathrm{~mL}$ distilled water with sonicated for $30 \mathrm{~min}$, and then $200 \mathrm{mg}\left(\mathrm{NH}_{4}\right)_{2} \mathrm{MoS}_{4}$ were added into the above mixture solution under vigorous stirring for another $24 \mathrm{~h}$. The relevant solid products were collected by centrifuged and washed with distilled water, and dried through a freeze-drying process. Third, the obtained powder was thermally treated at $450^{\circ} \mathrm{C}$ for $2 \mathrm{~h}$ and then $750^{\circ} \mathrm{C}$ for another $2 \mathrm{~h}$ under an $\mathrm{H}_{2} / \mathrm{Ar}$ flow. After cooling to room temperature, the $\mathrm{MoS}_{2} / \mathrm{G}$ HS was obtained.

\section{Preparation of $\mathrm{MoS}_{2} / \mathrm{G} \mathrm{MP}, \mathrm{G}$, and $\mathrm{MoS}_{2} / \mathrm{G} \mathrm{MM}$}

The pure $\mathrm{MoS}_{2}$ micron particles $\left(\mathrm{MoS}_{2} \mathrm{MP}\right)$ and pure $\mathrm{G}$ were obtained by directly thermal treatment under an $\mathrm{H}_{2} / \mathrm{Ar}$ flow from the $\left(\mathrm{NH}_{4}\right)_{2} \mathrm{MoS}_{4}$ and GO power, respectively. The $\mathrm{MoS}_{2} / \mathrm{G}$ MM was synthesized by mechanical mixture of $\mathrm{MoS}_{2} \mathrm{MP}$ and $\mathrm{G}$ with the appropriate molar concentration ratios of $82.1: 17.9$.

\section{Electrochemical Measurements}

The electrocatalytic activity measurements were performed by a CHI 660D electrochemical workstation in $\mathrm{N}_{2}$ saturated $1.0 \mathrm{M} \mathrm{KOH}$ and $0.5 \mathrm{M} \mathrm{H}_{2} \mathrm{SO}_{4}$ solutions. The as-synthesized 
catalysts covered on the carbon fiber papers were the working electrode with the mass of 1.5 $\mathrm{mg} \mathrm{cm}{ }^{-2}$, and a graphite rod and $\mathrm{Ag} / \mathrm{AgCl}$ electrode can selected as the counter and reference electrodes, respectively. All current densities presented were corrected against ohmic potential drop. The $1000^{\text {th }}$ cyclic voltammetry curves $(\mathrm{CVs})$ measurement were conducted between 0.2 and $-0.28 v s$. the reversible hydrogen electrode (RHE) in $0.5 \mathrm{M} \mathrm{H}_{2} \mathrm{SO}_{4}$ solution $(0.2$ and -0.32 vs. RHE in $1.0 \mathrm{M} \mathrm{KOH}$ solution) to investigate the stability of $\mathrm{MoS}_{2} / \mathrm{G}$ HS. Electrochemical impedance spectroscopy (EIS) were measured in a frequency range from $0.1 \mathrm{~Hz}$ to $100 \mathrm{kHz}$. All the measured potentials were corrected $v s$. RHE by the Nernst equation: $\mathrm{E}_{\mathrm{RHE}}=\mathrm{E}_{\mathrm{Ag} / \mathrm{AgCl}}+$ $0.059 \times \mathrm{pH}+0.197 \mathrm{~V}$

\section{Structure Characterizations}

The crystal structure of catalysts were measured by X-ray diffractometer (PANalytical X'Pert PRO) with $\mathrm{Cu} \mathrm{K} \alpha$ radiation $(\lambda=1.5418 \AA)$ at $40 \mathrm{kV}$ and $40 \mathrm{~mA}$. The morphology and microstructures were characterized by scanning electron microscope (Hitachi SU8010, 15 kV) and transmission electron microscopy (Tecnai G2 F30, $200 \mathrm{kV}$ ). X-ray photoelectron spectroscopy and Raman spectra analyses were carried out by using a spectrometer with $\mathrm{Al} \mathrm{K} \alpha$ radiation (Nepean, ON) and Renishaw INVIA. The contact angle was measured by the instrument from POWEREACH (JC2000D5, 220V).

\section{Computational details}

DFT calculations were performed using the projector augmented wave (PAW) formalism within the generalized gradient approximation (GGA) method with Perdew-Burke-Ernzerhof (PBE) exchange-correlation functional as implemented in Vienna Ab Initio Simulation Package (VASP). ${ }^{1}$ The cutoff energy of $500 \mathrm{eV}$ for the plane-wave basis set has been consistently used in all calculations. The convergence criterion of $0.05 \mathrm{eV} / \mathrm{A}$ was used for the forces in geometry optimizations and $10^{-4} \mathrm{eV}$ was used for the energy convergence. The rev-vdW-DF2 method proposed by Hamada was employed to include the dispersion contribution for the adsorption. ${ }^{2}$ According to experimental observation, the pristine $2 \mathrm{H}-\mathrm{MoS}_{2}$ has the lattice parameters of 
$a=3.16 \AA$ and $c=12.29 \AA .{ }^{3}$ In this work, the lattice parameters of $2 \mathrm{H}-\mathrm{MoS}_{2}$ unit cell optimized with a $10 \times 10 \times 3$ Monkhorst-Pack grid were $a=3.17 \AA$ and $c=12.33 \AA$ (interlayer distance 6.17 $\AA)$, in good agreement with the experimental values. ${ }^{4}$ The lattice parameter of graphene $(a=2.46$ $\AA$ ) is distinct from $\mathrm{MoS}_{2}$ by $22 \%$. To construct the heterostructure of $\mathrm{MoS}_{2}$ and graphene, a $4 \times 4$ supercell of $\mathrm{MoS}_{2}$ and a $5 \times 5$ supercell of graphene were used. The difference of lattice parameters then reduced to $3 \%$. Considering the experimental interlayer distance was determined to be $11 \AA$ for the heterostructure in this work, the $c$ vector was fixed to $22 \AA$ (double the interlayer distance) during the optimization while $a$ vector was relaxed; the optimized $a$ vector of the heterostructure was $12.43 \AA$. The vaccum for the edge model was set to be at least $10 \AA$.
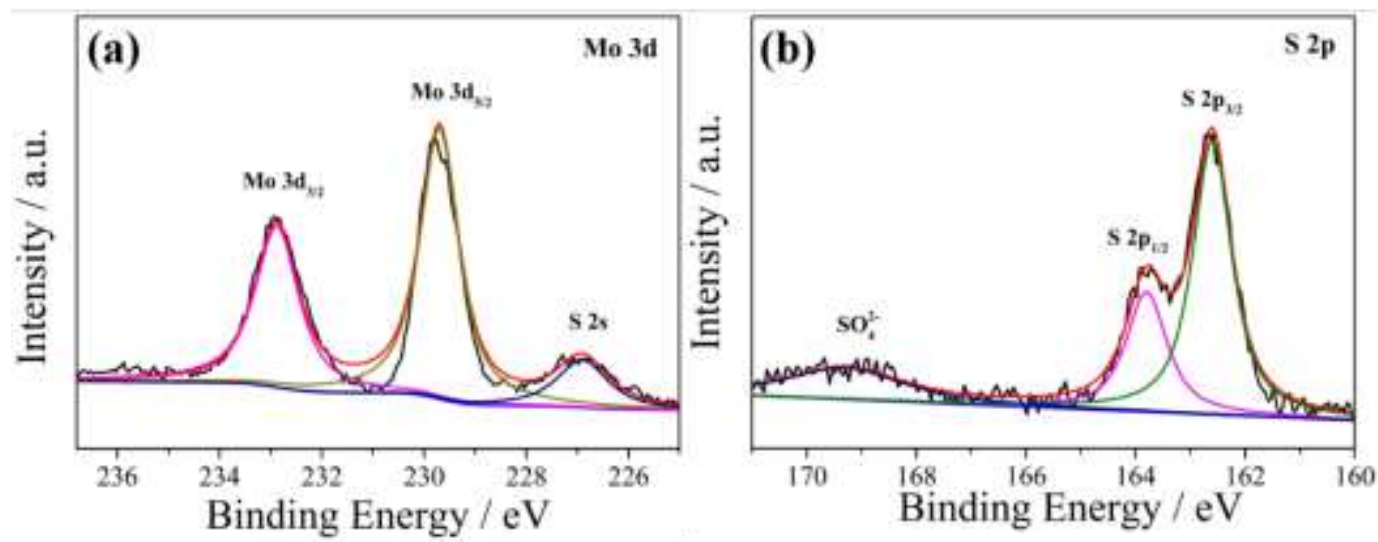

Figure S1. XPS spectra of Mo 3d (a) and S 2p (b) in $\mathrm{MoS}_{2} / \mathrm{G}$ HS electrodes toward HER. 


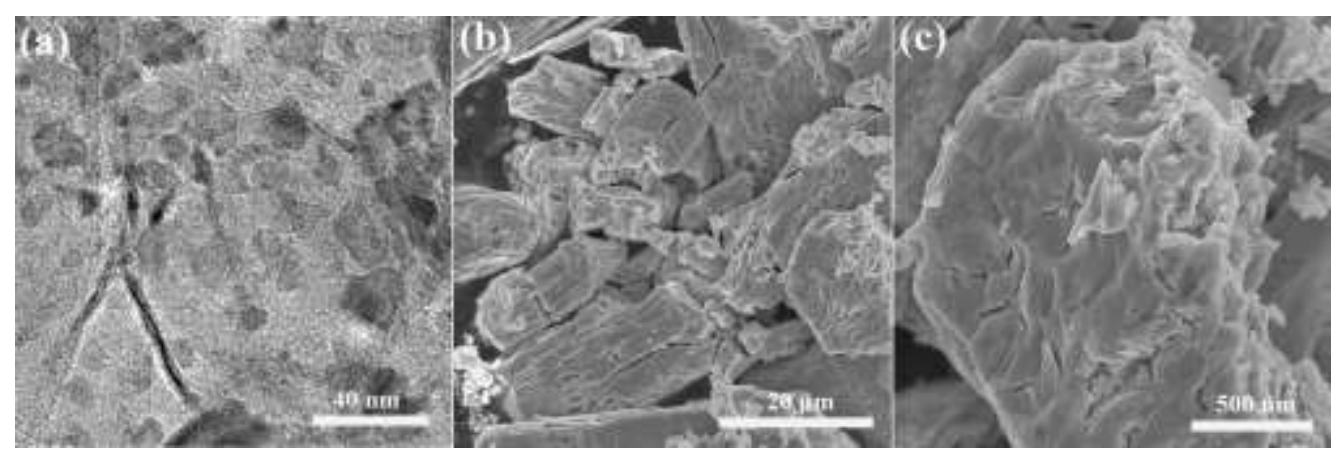

Figure S2. (a) Low-resolution TEM image of $\mathrm{MoS}_{2} / \mathrm{G}$ HS, (b-c) SEM images of $\mathrm{MoS}_{2} \mathrm{MP}$.

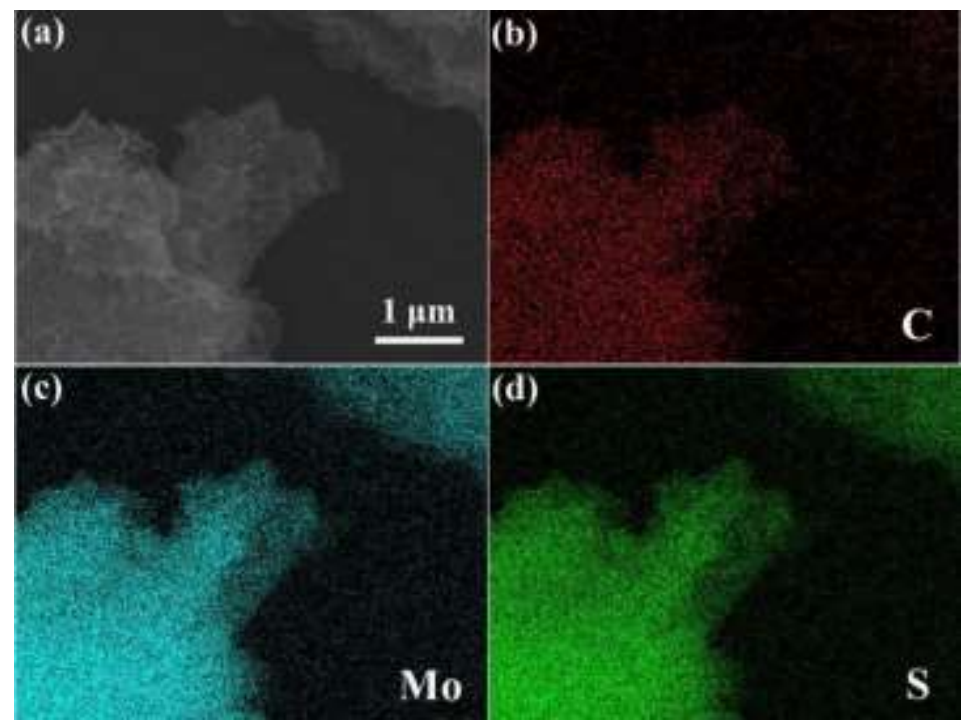

Figure S3. (a-d) Element mapping images of C, Mo, S in $\mathrm{MoS}_{2} / \mathrm{G} \mathrm{HS}$.
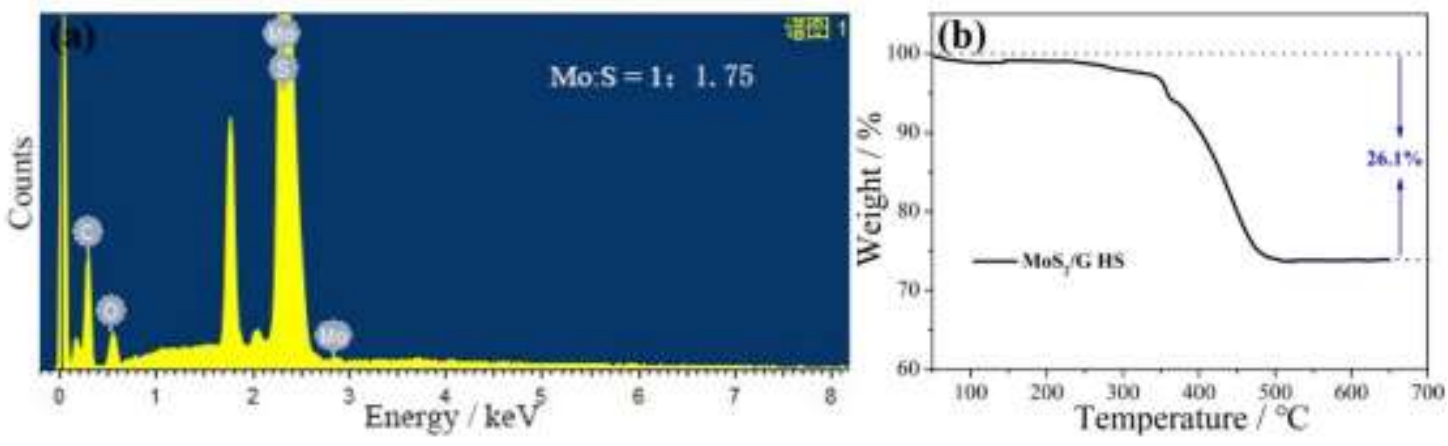

Figure S4. (a) EDS image and (b) TG curve of $\mathrm{MoS}_{2} / \mathrm{G}$ HS. 

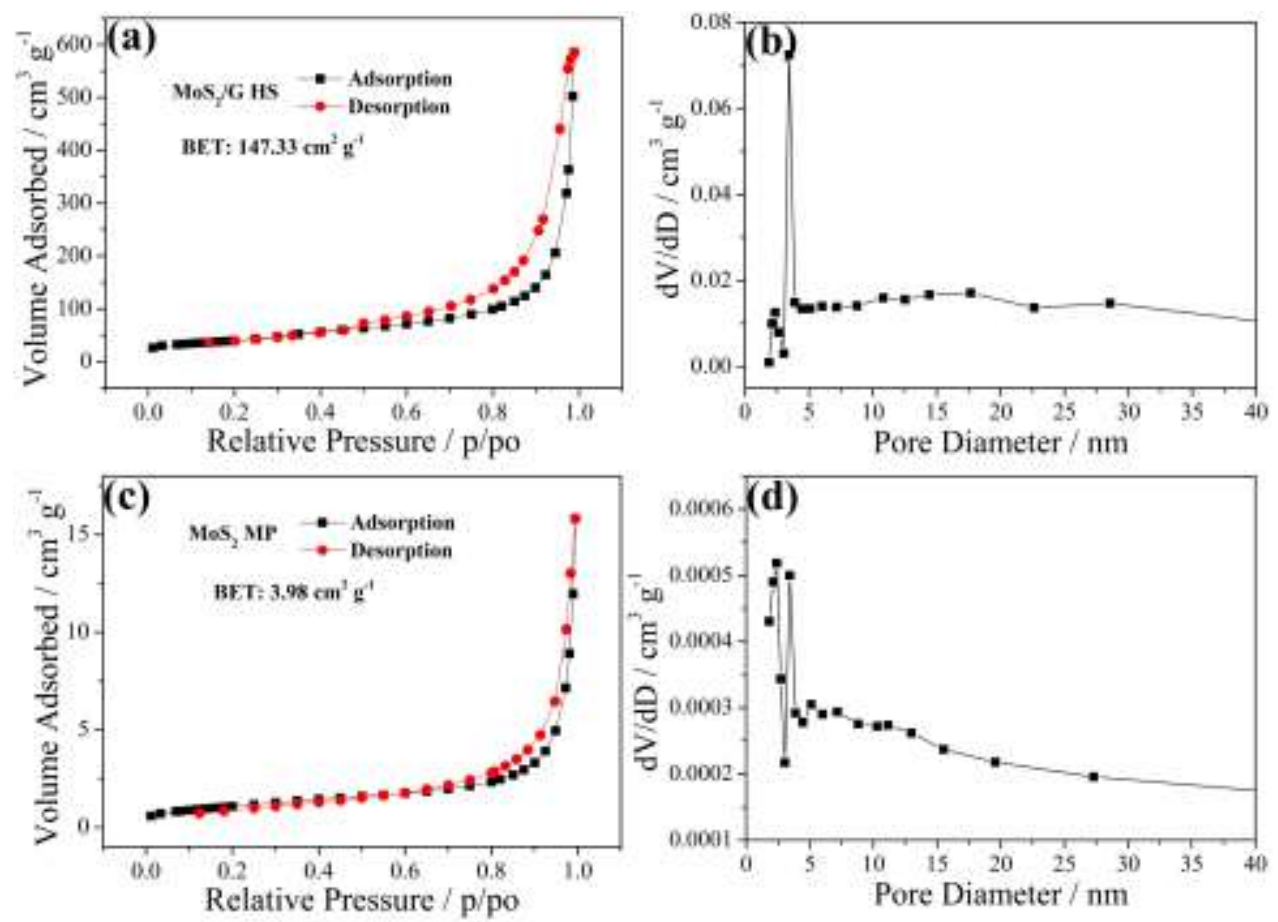

Figure S5. (a, c) Nitrogen adsorption and desorption isotherms and (b, d) the corresponding pore-size distribution calculated of $\mathrm{MoS}_{2} / \mathrm{G}$ HS and $\mathrm{MoS}_{2} \mathrm{MP}$.
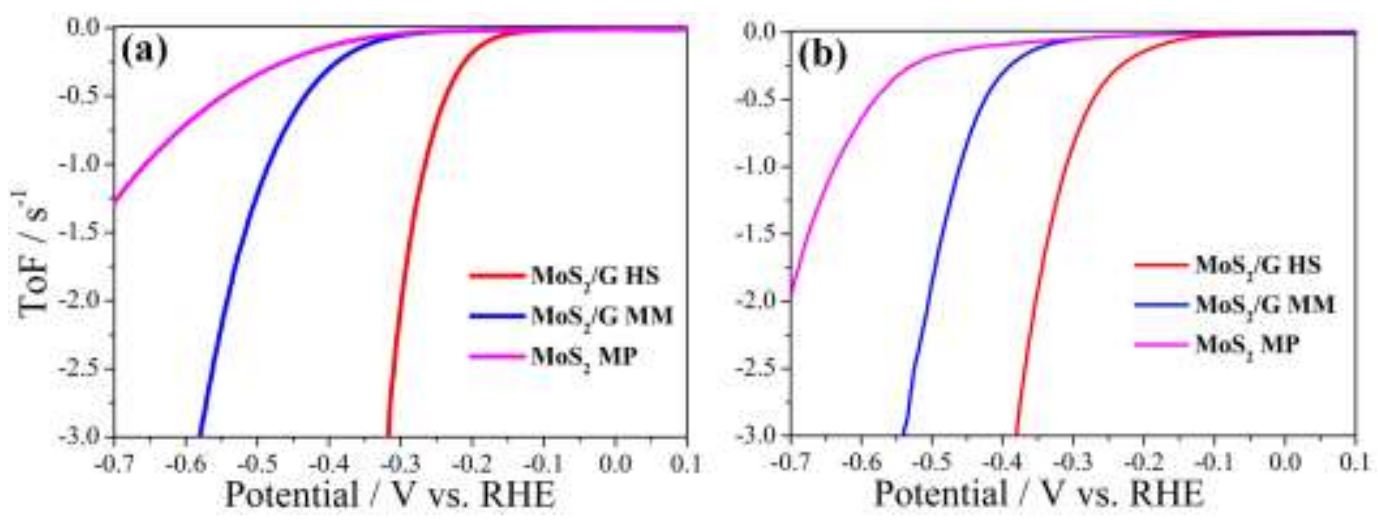

Figure S6. Calculated turnover frequencies for $\mathrm{MoS}_{2} / \mathrm{G} \mathrm{HS}$ electrode films in (a) $0.5 \mathrm{M} \mathrm{H}_{2} \mathrm{SO}_{4}$ and (b) $1.0 \mathrm{M} \mathrm{KOH}$ solutions. 

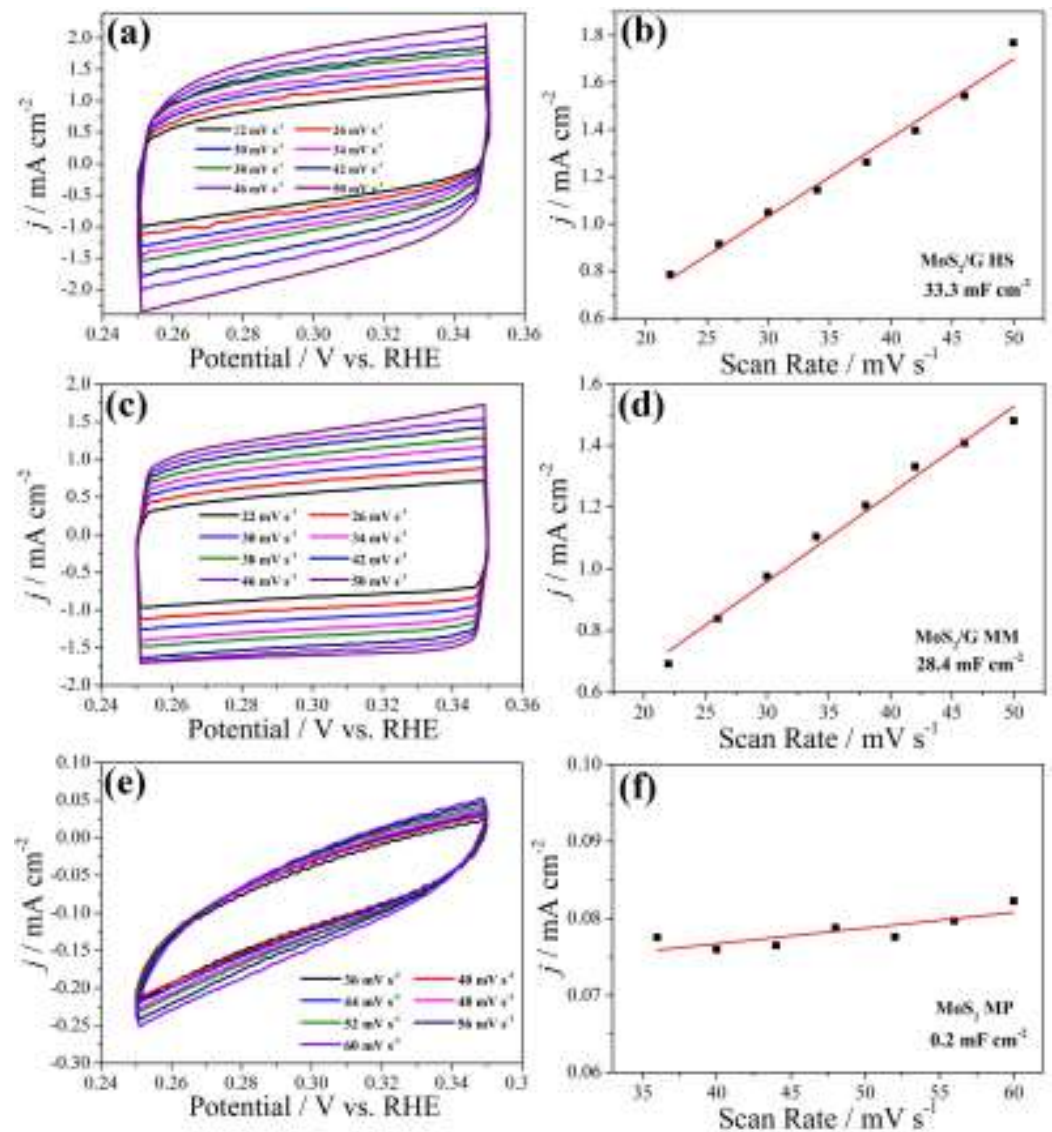

Figure S7. Cyclic voltammograms in the region of $0.25-0.35 \mathrm{~V} v s$. RHE for (a) $\mathrm{MoS}_{2} / \mathrm{G} \mathrm{HS}$, (c) $\mathrm{MoS}_{2} / \mathrm{G} \mathrm{MM}$ and (e) $\mathrm{MoS}_{2} \mathrm{MP}$ electrodes. The differences in current density at $0.3 \mathrm{~V} v s$. RHE plotted against scan rate fitted to a linear regression allows for the estimation of $C_{\mathrm{dl}}$ for (b) $\mathrm{MoS}_{2} / \mathrm{G} \mathrm{HS}$, (d) $\mathrm{MoS}_{2} / \mathrm{G} M M$ and (f) $\mathrm{MoS}_{2}$ MP electrodes.
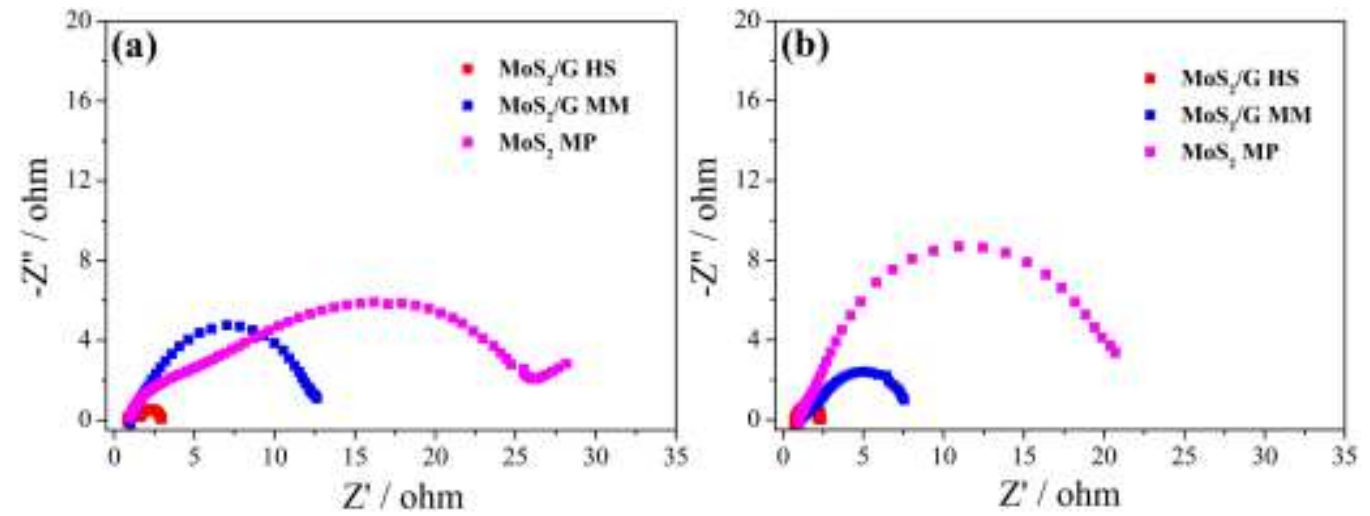

Figure S8. Nyquist plots for $\mathrm{MoS}_{2} / \mathrm{G} \mathrm{HS}$, (d) $\mathrm{MoS}_{2} / \mathrm{G} M \mathrm{M}$ and (f) $\mathrm{MoS}_{2} \mathrm{MP}$ electrodes for HER in (a) $0.5 \mathrm{M} \mathrm{H}_{2} \mathrm{SO}_{4}$ solution under the overpotentials of $300 \mathrm{mV}$ and b) $1.0 \mathrm{M} \mathrm{KOH}$ solution under the overpotentials of $350 \mathrm{mV}$. 


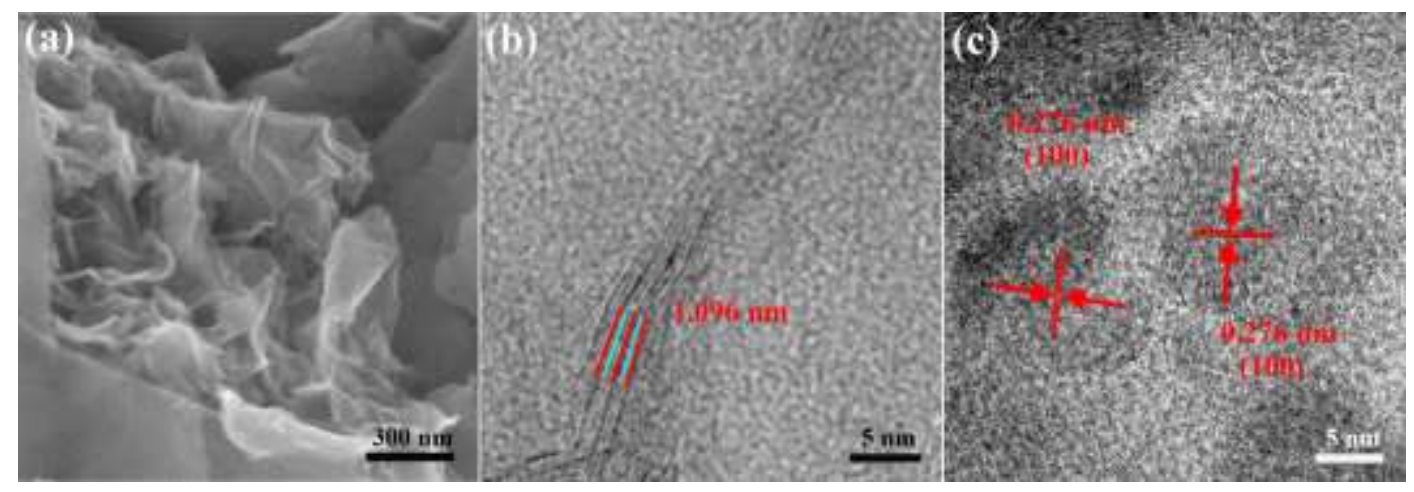

Figure S9. (a) Low-resolution SEM, and (b) HRTEM images of $\mathrm{MoS}_{2} / \mathrm{G}$ HS after HER process for $10 \mathrm{~h}$.

Table S1 Comparison of the HER activities of the $\mathrm{MoS}_{2} / \mathrm{G} H S, \mathrm{MoS}_{2} / \mathrm{G} \mathrm{MM}$, and $\mathrm{MoS}_{2} \mathrm{MP}$ catalysts in $0.5 \mathrm{M} \mathrm{H}_{2} \mathrm{SO}_{4}$ and $1.0 \mathrm{M} \mathrm{KOH}$ solutions with recently published results.

\begin{tabular}{|c|c|c|c|c|}
\hline Catalyst & $\begin{array}{c}\eta_{10} \\
(\mathrm{mV})\end{array}$ & $\begin{array}{l}\eta_{100} \\
(\mathrm{mV})\end{array}$ & Electrolyte & Ref. \\
\hline $\mathrm{Au}-\mathrm{MoS}_{2}$ & 280 & - & $0.5 \mathrm{M} \mathrm{H}_{2} \mathrm{SO}_{4}$ & [5] \\
\hline $\mathrm{MoS}_{2}$ & 187 & $\sim 240$ & $0.5 \mathrm{M} \mathrm{H}_{2} \mathrm{SO}_{4}$ & [6] \\
\hline P-doped 2H-MoS ${ }_{2}$ & 217 & $\sim 320$ & $0.5 \mathrm{M} \mathrm{H}_{2} \mathrm{SO}_{4}$ & [7] \\
\hline $\mathrm{MoS}_{2}$ nanodots & 248 & - & $0.5 \mathrm{M} \mathrm{H}_{2} \mathrm{SO}_{4}$ & [8] \\
\hline $\mathrm{MoS}_{2}$-cPAN & 185 & - & $0.5 \mathrm{M} \mathrm{H}_{2} \mathrm{SO}_{4}$ & [9] \\
\hline $\begin{array}{l}\mathrm{MoO}_{2} / \mathrm{MoS}_{2} \\
\text { nanofiber }\end{array}$ & 340 & - & $0.5 \mathrm{M} \mathrm{H}_{2} \mathrm{SO}_{4}$ & [10] \\
\hline V-doping $\mathrm{MoS}_{2}$ & 194 & $\sim 275$ & $0.5 \mathrm{M} \mathrm{H}_{2} \mathrm{SO}_{4}$ & [11] \\
\hline $\begin{array}{l}\text { metallic-Phase } \\
\mathrm{MoS}_{2}\end{array}$ & 210 & - & $0.5 \mathrm{M} \mathrm{H}_{2} \mathrm{SO}_{4}$ & [12] \\
\hline $\begin{array}{l}\text { edge-aligned - } \\
\text { 2H/1T-MoS } / \text { RGO }\end{array}$ & 186 & $\sim 230$ & $0.5 \mathrm{M} \mathrm{H}_{2} \mathrm{SO}_{4}$ & [13] \\
\hline $\begin{array}{l}\text { amorphous } \\
\text { phosphorus-doped } \\
\mathrm{MoS}_{2}\end{array}$ & 219 & - & $0.5 \mathrm{M} \mathrm{H}_{2} \mathrm{SO}_{4}$ & [14] \\
\hline $\begin{array}{l}\text { oxygen- } \\
\text { incorporated } \mathrm{MoS}_{2}\end{array}$ & $\sim 185$ & $\sim 290$ & $0.5 \mathrm{M} \mathrm{H}_{2} \mathrm{SO}_{4}$ & [15] \\
\hline defect-rich $\mathrm{MoS}_{2}$ & $\sim 190$ & - & $0.5 \mathrm{M} \mathrm{H}_{2} \mathrm{SO}_{4}$ & [16] \\
\hline $\mathrm{Co}-\mathrm{BDC} / \mathrm{MoS}_{2}$ & 248 & - & $1.0 \mathrm{M} \mathrm{KOH}$ & [17] \\
\hline $\begin{array}{l}1 \mathrm{~T}-2 \mathrm{H} \mathrm{MoS}_{2} \\
\text { Heterostructures }\end{array}$ & $\sim 280$ & - & $1.0 \mathrm{M} \mathrm{KOH}$ & [18] \\
\hline $\mathrm{Ni}(\mathrm{OH})_{2} / \mathrm{MoS}_{2}$ & 227 & - & $1.0 \mathrm{M} \mathrm{KOH}$ & [19] \\
\hline
\end{tabular}




\begin{tabular}{lcccc}
$\mathrm{MoS}_{2} \mathrm{MP}$ & 383 & 675 & $0.5 \mathrm{M} \mathrm{H}_{2} \mathrm{SO}_{4}$ & This work \\
& 436 & 647 & $1.0 \mathrm{M} \mathrm{KOH}$ & \\
$\mathrm{MoS}_{2} / \mathrm{G} \mathrm{MM}$ & 343 & 494 & $0.5 \mathrm{M} \mathrm{H}_{2} \mathrm{SO}_{4}$ & This work \\
& 348 & 468 & $1.0 \mathrm{M} \mathrm{KOH}$ & \\
$\mathrm{MoS}_{2} / \mathrm{G} \mathrm{HS}$ & 180 & 268 & $0.5 \mathrm{M} \mathrm{H}_{2} \mathrm{SO}_{4}$ & This work \\
& 183 & 313 & $1.0 \mathrm{M} \mathrm{KOH}$ & \\
\hline
\end{tabular}

\section{References}

(1) Perdew, J. P.; Burke, K.; Ernzerhof, M. Generalized Gradient Approximation Made Simple. Phys. Rev. Lett. 1996, 77, 3865-3868.

(2) Hamada, I. Van der Waals Density Functional Made Accurate. Phys. Rev. B 2014, 89, 121103.

(3) Jellinek, F.; Brauer, G.; MÜLler, H. Molybdenum and Niobium Sulphides. Nature 1960, $185,376$.

(4) Monkhorst, H. J.; Pack, J. D. Special Points for Brillouin-Zone Integrations. Phys. Rev. B 1976, 13, 5188-5192.

(5) Zhao, S.; Jin, R.; Song, Y.; Zhang, H.; House, S. D.; Yang, J. C.; Jin, R. Atomically Precise Gold Nanoclusters Accelerate Hydrogen Evolution over $\mathrm{MoS}_{2}$ Nanosheets: The Dual Interfacial Effect. Small 2017, 13, 1701519.

(6) Lukowski, M. A.; Daniel, A. S.; Meng, F.; Forticaux, A.; Li, L.; Jin, S. Enhanced Hydrogen Evolution Catalysis from Chemically Exfoliated Metallic $\mathrm{MoS}_{2}$ Nanosheets. J. Am. Chem. Soc. 2013, 135, 10274-10277.

(7) Huang, X.; Leng, M.; Xiao, W.; Li, M.; Ding, J.; Tan, T. L.; Lee, W. S. V.; Xue, J. Activating Basal Planes and S-Terminated Edges of $\mathrm{MoS}_{2}$ toward More Efficient Hydrogen Evolution. Adv. Funct. Mater. 2017, 27, 1604943.

(8) Benson, J.; Li, M.; Wang, S.; Wang, P.; Papakonstantinou, P. Electrocatalytic Hydrogen Evolution Reaction on Edges of a Few Layer Molybdenum Disulfide Nanodots. ACS Appl. Mater. Interfaces 2015, 7, 14113-14122.

(9) Zeleke, T. S.; Tsai, M.-C.; Weret, M. A.; Huang, C.-J.; Birhanu, M. K.; Liu, T.-C.; Huang, C.-P.; Soo, Y.-L.; Yang, Y.-W.; Su, W.-N.; Hwang, B.-J. Immobilized Single Molecular Molybdenum Disulfide on Carbonized Polyacrylonitrile for Hydrogen Evolution Reaction. ACS Nano 2019, 13, 6720-6729. 
(10)Rheem, Y.; Han, Y.; Lee, K. H.; Choi, S.-M.; Myung, N. V. Synthesis of Hierarchical $\mathrm{MoO}_{2} / \mathrm{MoS}_{2}$ Nanofibers for Electrocatalytic Hydrogen Evolution. Nanotechnology 2017, 28,105605 .

(11)Bolar, S.; Shit, S.; Kumar, J. S.; Murmu, N. C.; Ganesh, R. S.; Inokawa, H.; Kuil, T. Optimization of Active Surface Area of Flower Like $\mathrm{MoS}_{2}$ Using V-Doping Towards Enhanced Hydrogen Evolution Reaction in Acidic and Basic medium. Applied Catalysis B: Environmental 2019, 254, 432-442.

(12)Wang, J.; Wang, N.; Guo, Y.; Yang, J.; Wang, J.; Wang, F.; Sun, J.; Xu, H.; Liu, Z.-H.; Jiang. R. Metallic-Phase $\mathrm{MoS}_{2}$ Nanopetals with Enhanced Electrocatalytic Activity for Hydrogen Evolution. ACS Sustainable Chem. Eng. 2018, 6, 13435-13442.

(13) You, B.; Jiang, N.; Sheng, M.; Yano, J.; Sun, Y. High-Performance Overall Water Splitting Electrocatalysts Derived from Cobalt-Based Metal-Organic Frameworks. Chem. Mater. 2015, 27, 7636-7642.

(14)Wang, D.; Xie, Y.; Wu, Z. Amorphous Phosphorus-Doped $\mathrm{MoS}_{2}$ Catalyst for Efficient Hydrogen Evolution Reaction. Nanotechnology 2019, 30, 205401.

(15)Xie, J.; Zhang, J.; Li, S.; Grote, F.; Zhang, X.; Zhang, H.; Wang, R.; Lei, Y.; Pan, B.; Xie, Y. Controllable Disorder Engineering in Oxygen-Incorporated $\mathrm{MoS}_{2}$ Ultrathin Nanosheets for Efficient Hydrogen Evolution. J. Am. Chem. Soc. 2013, 135, 17881-17888.

(16)Xie, J.; Zhang, H.; Li, S.; Wang, R.; Sun, X.; Zhou, M.; Zhou, J.; Lou, X. W.; Xie, Y. Defect-Rich $\mathrm{MoS}_{2}$ Ultrathin Nanosheets with Additional Active Edge Sites for Enhanced Electrocatalytic Hydrogen Evolution. Adv. Mater. 2013, 25, 5807-5813.

(17)Zhu, D.; Liu, J.; Zhao, Y.; Zheng Y.; Qiao, S. Engineering 2D Metal-Organic Frameworks/MoS 2 Interface for Enhanced Alkaline Hydrogen Evolution. Small 2019, 15, 1805511.

(18)Wang, S.; Zhang, D.; Li, B.; Zhang, C.; Du, Z.; Yin, H.; Bi, X.; Yang, S. Ultrastable InPlane 1T-2H MoS 2 Heterostructures for Enhanced Hydrogen Evolution Reaction. Adv. Energy Mater. 2018, 8, 1801345.

(19)Zhao, G.; Lin, Y.; Rui, K.; Zhou, Q.; Chen, Y.; Dou, S. X.; Sun, W. Epitaxial Growth of $\mathrm{Ni}(\mathrm{OH})_{2}$ Nanoclusters on $\mathrm{MoS}_{2}$ Nanosheets for Enhanced Alkaline Hydrogen Evolution Reaction. Nanoscale 2018, 10, 19074-19081. 